\title{
ビトリファイド超砥粒砥石の作業面の形状モデリング*
}

\author{
樋口誠 宏*1, 山口智実*1 \\ 松森昇 ${ }^{* 2}$, 尾 倉 秀 一*2
}

\section{Geometric Modeling of Vitrified Superabrasive Stone Surface}

\author{
Masahiro HIGUCHI*3, Tomomi YAMAGUCHI, \\ Noboru MATSUMORI and Hidekazu OGURA \\ *3 Department of Mechanical Engineering, Kansai University, \\ 3-3-35 Yamate-cho, Suita-shi, Osaka, 564-8680 Japan
}

\begin{abstract}
A geometric modeling technique of the complex vitrified superabrasive stone surfaces has been developed for the purpose of describing their topographies with desired characteristics. It is based on the generating algorithms for random fractals, such as midpoint displacement and successive random additions, and yields a three-dimensional topographic map of the stone surface. Comparisons between the simulated topographic map and the measured one show a good match; the spatial distribution of abrasives on both the stone surfaces exhibits a fractal structure, indicating that the simulated stone surface is a good representation of the real one. Therefore, the computer modeling could be used advantageously when the designer makes drawings of stone surfaces.
\end{abstract}

Key Words: Grinding, Design, Modeling, Fractal, Superabrasive Stone, Surface Topography

\section{1. 緒言}

砥石作業面は材料除去と表面創成の機能をもつ表面 であるため, その設計は非常に重要である。ところが, 設計者はイメージする砥石作業面トポグラフィをポン チ絵で表す以外の手段をもたないため，試作した砥石 の作業面の写真を見ながら,イメージに近いトポグラ フィをもつ試作砥石の製造条件を設計解として選定し ている.このような設計プロセスに頼らざるを得ない 理由は, 複雑で不規則な砥石作業面のモデリング方法 が確立されていないからである。

このような状況の中で, 砥石作業面トポグラフィを コンピュータ上で仮想的に生成する研究が行われてい る. 水谷ら (1) は, 長短径比の異なる砥粒モデルを正方 格子点や面心立方格子点にランダムに配置する作業面 モデルを考案し，実際の作業面上の砥粒の偏在状態が 表現できると述べている，しかしながら，このモデル には砥石作業面が統計的にフラクタルな構造を示すと いう特徵(2)(3) が反映されていない, 具体的にいえば,

* 原稿受付 2007 年 1 月 25 日.

*1 正員, 関西大学工学部(画 564-8680 吹田市山手町 3-3-35).

*2 (株)ミズホ(丞610-0121 城陽市寺田袋尻 82).

E-mail : higuchi@ipcku.kansai-u.ac.jp
砥石作業面のプロフィールはそれを $1 / a$ に縮小した 相似図形 $b$ 個によって構成されているという特徴が 備わっていない. そのため, フラクタル構造を特徴づ けるフラクタル次元 $D=\log _{a} b$ を使って, 砥石作業面 モデルをコンピュータ上で生成する方法(4)(5) が検討さ れた．また，結合剤で架橋された砥粒間を気孔が介在 する砥石の構造が砥粒, 結合剂, 気孔剤などの粒子の 混合かくはん, 圧縮成形, 焼成工程に従って形成され る点を考慮して, そのモデルをフラクタル幾何学の分 野で提案されている手法を使って生成する方法 ${ }^{(6)}$ も 検討されている.しかし, それらの手法を砥石の形態 設計に役立てるには, 砥石の内部構造と作業面のモデ ル間に相互関連性がなければならない.さもないと, 設計解である砥石製造条件を得ることができないから である。

そこで, 砥石の構成要素に関するデータから砥石の 内部構造モデルを生成し, そのフラクタル構造を特徴 づける次元を基に，作業面のモデルを生成する総合的 なモデリング手法を開発した。このとき, 砥石の構造 ならびに作業面の形態がフラクタルであるという点を 考慮して, フラクタル・モデリングの手法を一貫して 適用することを試みた。 


\section{2. 砥石作業面の形状モデリングの概要}

図 1 は形状モデリングの方法を開発しようとするビ トリファイド超砥粒砥石の内部構造を示す.

図 2 は砥石の構成要素に関するデー夕を与えて, 砥 石の内部構造と作業面のモデルを構成する流れを示し ている．モデリングの手順は基本的にビトリファイド 砥石の製造工程に従っている。まず混合かくはん工程 では，砥粒，結合剤および気孔剤の粒子が凝集するこ とにより，クラスタが形成されるので，このモデルを ブラウン運動する粒子が別の粒子に衝突して付着する 拡散律速凝集シミュレーションにより作成する。続く 焼成工程では，気孔剂粒子が焼失して大気孔が形成さ れる。また，溶融した結合剤が砥粒を濡らし，冷却過 程でそれが磁器質化して砥粒間を架橋し, 砥石構造が 形成される，そこで，このモデルを前述のクラスタモ

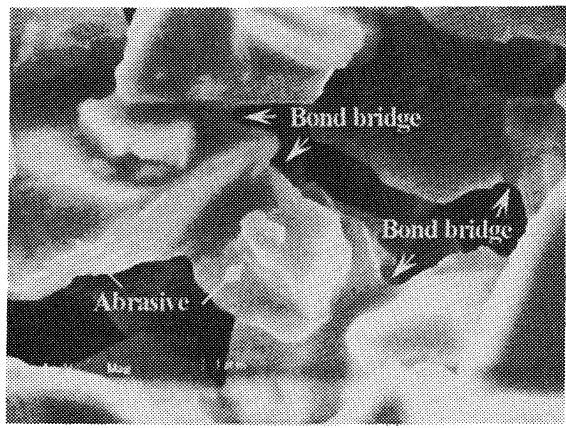

Fig. 1 Internal structure of vitrified CBN stone
デル中の気孔剤粒子の除去と, 砂山崩落シミュレーシ ヨンによる結合橋の形成によって作成する。

以上に述べたモデリングの詳細は既報(7) に譲るが, 作成されたモデルの一例を図 3 に示して, その特徴を 簡単に記す。本モデルは正四面体や正六面体の頂点に 砥粒を配置し，それらを円柱の結合橋で架橋した従来 の砥石モデルとは構造的にかなり違っている。砥粒の 配置は不規則であり，砥粒間距離，砥粒を保持する結 合橋の数や向きなどはそれぞれに異なっていて, 図 1 に示した砥石構造の複雑さが表現されている.

本論文は上述の研究を発展させて, 砥石の内部構造 モデルを基に，形態的，視賞的に類似する砥石作業面 モデルを構成する方法を開発するものである，すなわ ち, 構造モデルの任意の切断面に現れる砥粒の分布の フラクタル次元を解析し, それをパラメータに中点変 位法と逐次ランダム加算法を適用して, 実際の作業面 に類似するモデルが得られるか否かを検討する。

\section{3. 砥粒の空間分布のフラクタル解析}

図 4 はレーザ顕微鏡で測定したビトリファイド $\mathrm{CBN}$ 砥石の作業面の鳥瞰図と, 砥石表面から $1 / 2$ 砥 粒径の深さの範囲に存在する砥粒を表している。い ま，図 4(b)において，ある砥粒を中心に半径 $r$ の円 を描き, この円の内部に存在する砥粒の数 $M(r)$ を数 える。このとき，砥粒が直線的に連続して分布してい ると, $M(r) \propto r^{1}$ となり, 平面を一様に連続して分布 していると， $M(r) \propto r^{2}$ となるのは明らかである。と ころが，砥粒は規則的に連続して並んでいないので,

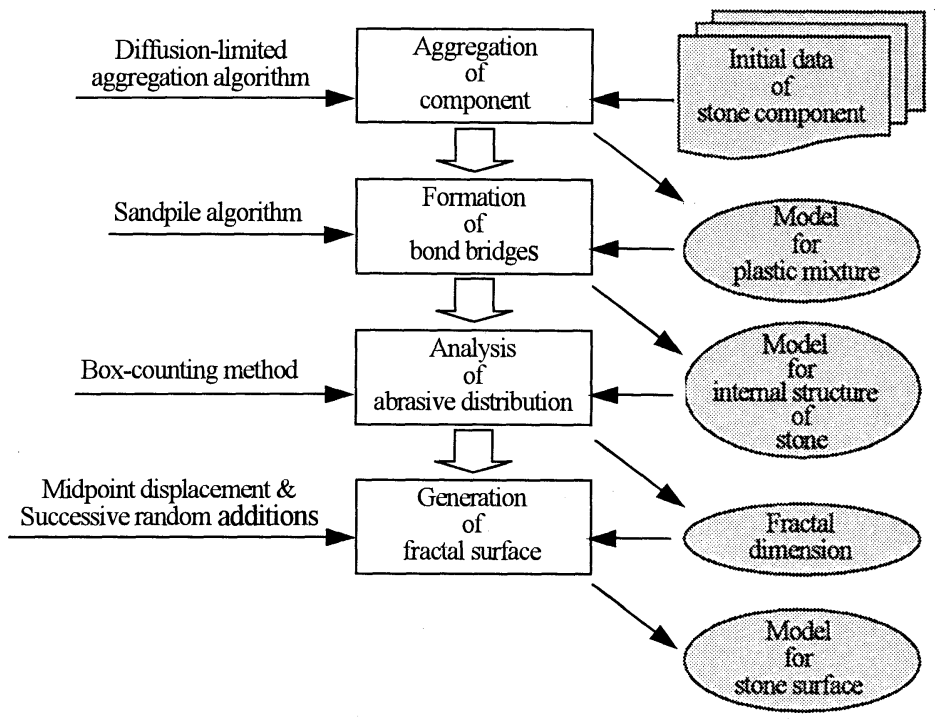

Fig. 2 Flow chart for generating model of stone surface 
砥粒数 $M(r)$ の半径 $r$ に対する変化は, 図 6 に示すよ うに両対数座標上で, $M(r) \propto r^{1.46}$ のようにスケーリ ングされる.ここで, 非整数の指数 1.46 はフラクタ ル次元と呼ばれ，砥粒の分布がランダムでも規則的で もなく，統計的にフラクタルであると認識すべきであ ることを示唆している.

同様に, 砥石の構造モデルの砥粒分布を解析すると, 次のようになる。まず, 図 4 に示した粒度 4000 , 集中 度 117 のビトリファイド $\mathrm{CBN}$ 砥石の構成要素の重量 百分率を用いて, 粒子総数 6000 個の砥石の構造モデ ルを作成した，次に，これを任意の平面で切断し，中 心が切断面より下にある砥粒のみが砥石表面に存在す ると考えて, 砥石表面のモデルを作成した，それが図 5 である.このモデルの砥粒数 $M(r)$ と半径 $r$ の関係 を調べた結果を, 図 6 のプロット○に示す。図 6 より, 両者の間にはスケーリング則が成り立ち, そのフラク タル次元は 1.44 と与えられる。このようにモデルの 砥粒分布のフラクタル次元が実砥石の次元と一致する ことから, 提案する砥石構造のモデルが実砥石の構造 に類似しているといえる。

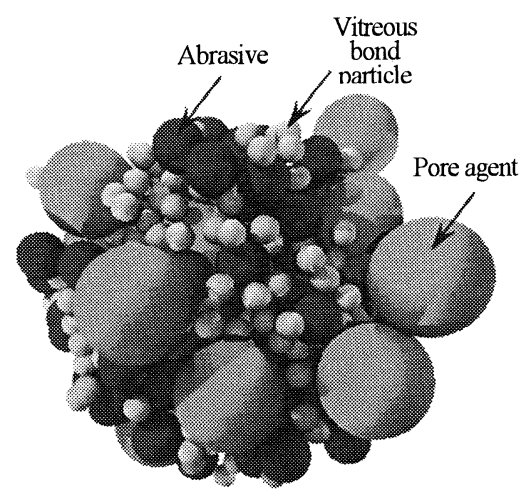

(a) Model for plastic mixture

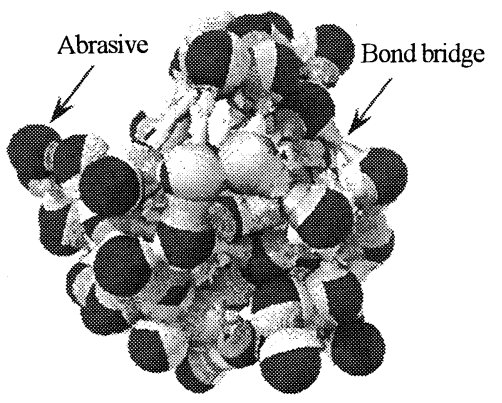

(b) Model for internal structure of stone

Fig. 3 Structure model for vitrified stone obtained by computer simulation using diffusion-limited aggregation algorithm and sandpile algorithm

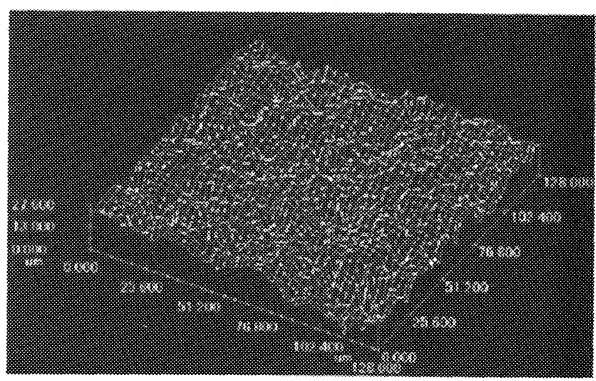

(a) Bird's-eye view

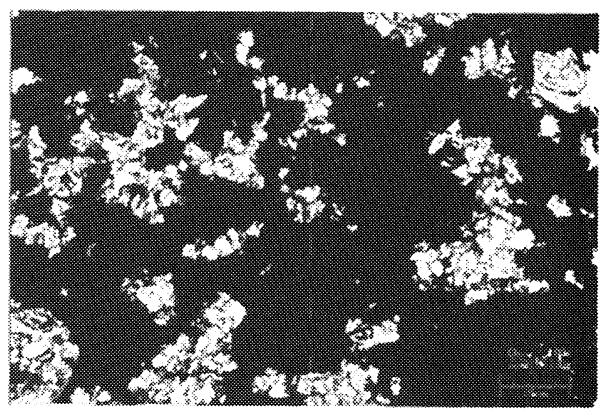

(b) Plane view

Fig. 4 Distribution of abrasives over vitrified CBN stone surface (Abrasive size: 4000 , Concentration: 117)

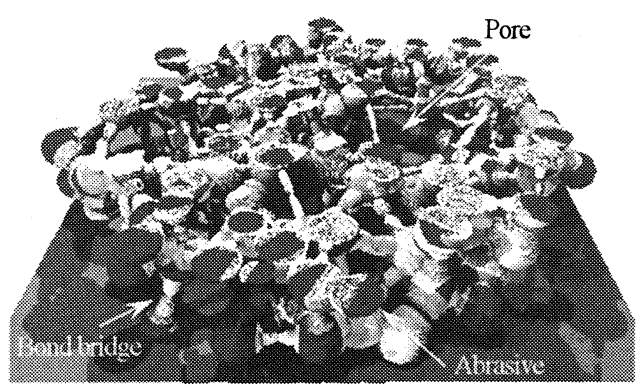

Fig. 5 Distribution of abrasives on simulated stone surface

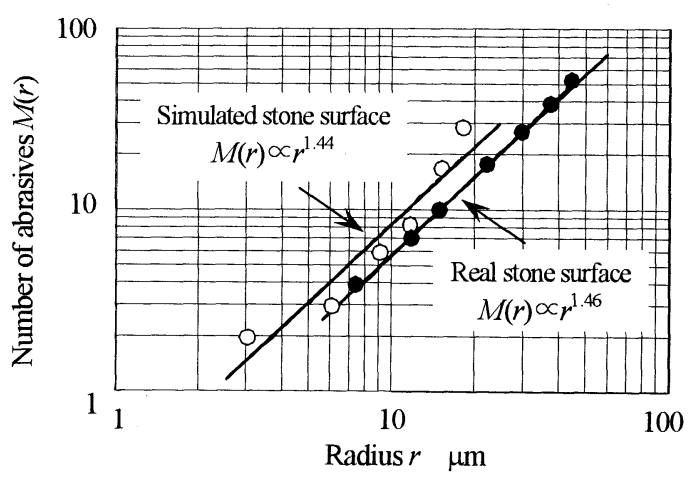

Fig. 6 Comparison of distribution of abrasives on the real and the simulated stone surfaces 


\section{4. 砥石作業面モデルの 構成アルゴリズム}

砥粒がフラクタル分布する砥石表面のモデルを図 5 に示したが, 実際の砥石作業面と比べると, 視覚的に 相違している印象は否めない.そこで, 視覚的にも類 似する作業面モデルを構成する方法について検討し た.

砥石作業面の形態はユークリッド幾何図形とかなり 異なるので, 機械部品を直方体, 円柱, 三角すいなど のプリミティブの集合として形状表現する CSGを適 用して, 砥石作業面を描くのは難しい. そのため, フ ラクタルな構造をもつ砥石作業面のモデルを得るに は, フラクタル・グラフィックスの手法を用いるのが 妥当であると考え, 中点変位法と逐次ランダム加算法 を適用した，以下に，それらのアルゴリズム ${ }^{(8)}$ を記 す.

（1）単位長さの正方格子を用意する. また, 平均 が零で分散が $\sigma^{2}$ の乱数を発生するガウス確率変数 ogauss（）を用意する.

（2） ガウス確率変数 $\sigma$ gauss（）が与える值によ り, 正方格子の 4 点 $(0,0),(1,0),(0,1),(1,1) の$ 高 さ $h_{0}(i, j)$ を決める.

（3）正方格子を図 7 に示すように, $4^{n}$ 個の正方格 子に分割する. $n$ を分割の回数とすると, $n$ 回分割し た後の正方格子の辺の長さは, $2^{-n / 2}$ となる.

（4）正方格子の分割に合わせて, 分散を $2^{-2 H n}$ 倍 する.すなわち, ガウス確率変数を $2^{-H n}$ ogauss（） に変更する.ここで, $H$ は後述のハースト指数であ る.

（5）正方格子を分割する中点の高さ $h_{n}\left(2^{-n / 2}\right.$, $\left.2^{-n / 2}\right)$ を決める。これは周辺の 4 点の高さ $h_{n-1}(i, j)$ の平均值にガウス確率変数 $2^{-H n} \sigma$ gauss（）が与える ランダム変動量を加えた次式により決める. 図 8 は分

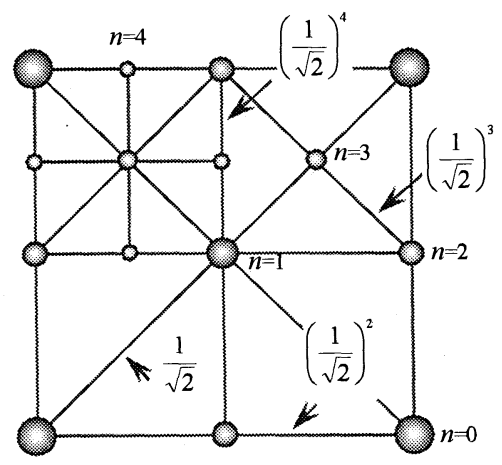

Fig. 7 Method of segmentation of square lattice
割 1 回めの中点の高さを決める過程を説明している.

$$
\begin{aligned}
h_{n} & {\left[\left(\frac{1}{\sqrt{2}}\right)^{n},\left(\frac{1}{\sqrt{2}}\right)^{n}\right] } \\
= & \sum_{i=0}^{1} \sum_{j=0}^{1} \frac{h_{n-1}(i, j)}{4}+2^{-H n} \text { ogauss( ) }
\end{aligned}
$$

（6）規定の分割回数まで, 再帰的にステップ（3） 〜 ( 5 )を繰返す.

さて, 上述のアルゴリズムに用いられているハース 卜指数 $H$ は, 正方格子を $2^{-1 / 2}$ に縮小するごとに, 中 点の高さのランダム変動量 $\Delta h$ を, 次式のスケーリン グ則に従って決めているパラメータである.

$$
\Delta h \propto\left(\frac{1}{\sqrt{2}}\right)^{H}
$$

このハースト指数を $0<H<1$ の範囲に限定すると, 正方格子の大きさと中点の高さはそれぞれ異なる比率 でスケーリングされ, 統計的に変わらない自己相似的 な形状が生成される。 また，上述の方法で作成された 形状をある平面で切ると, 切断面には自己相似的な点 の集合が現れる.この点の集合のフラクタル次元 $D$ はハースト指数 $H$ と次式の関係を満たす.

$$
D=2-H
$$

それゆえ, 平面上に分布する点の集合のフラクタル次 元は, 直線の一次元と平面の二次元の間の $1<D<2$ の範囲の值をもつ.このことは図 6 に示した砥石作業 面に存在する砥粒の分布状態を特徴づけるフラクタル 次元にも当てはまる.

以上のことから, 砥石作業面の砥粒分布のフラクタ ル次元をハースト指数に変換して, 上述のアルゴリズ ムを適用すると, 実際の砥石作業面に近いモデルが得 られるものと考えられる。

\section{5. 砥石作業面モデルと穴評価}

4 章のアルゴリズムに従って作成した砥石作業面の モデルを図 9 に示す。一見して, これらのモデルが実 際の砥石作業面の鳥瞰図に似ていると感じられる。図 示するモデルはハースト指数 $H=0.54$ 一定のもとに

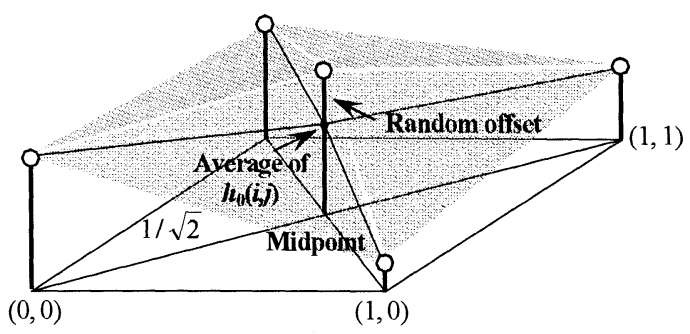

Fig. 8 First stage in midpoint displacement method and successive random addition method 
構成されたもので, ガウス確率変数の初期值がその形 態的変化に及ぼす影響を表している. 各モデルを比較 すると, 水平方向に対する垂直方向のスケーリングの 比率を決めるハースト指数が一定でも, ガウス確率変 数が与える值に応じて, 見掛け上, 違った形態のモデ ルが生成されることがわかる。このことは，適用した アルゴリズムが統計的に同じでも, 多様な様相を見せ る砥石作業面のモデリングに適していることを示して いる.

図 10 はハースト指数が砥石作業面モデルの形態的 変化に及ぼす影響を表している，モデルの垂直断面に

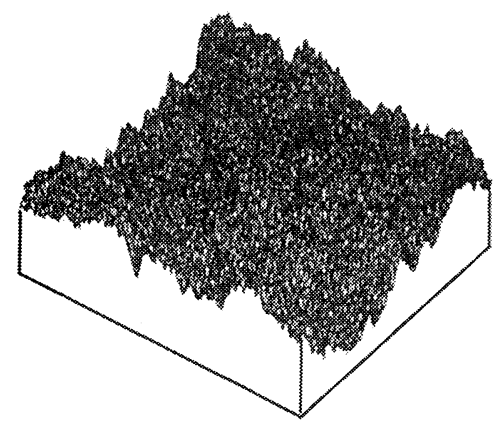

(a) $\operatorname{\sigma gauss}(\quad)=15000$

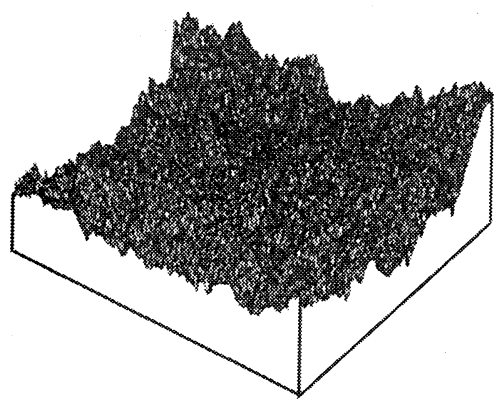

(b) $\operatorname{\sigma gauss}(\quad)=20000$

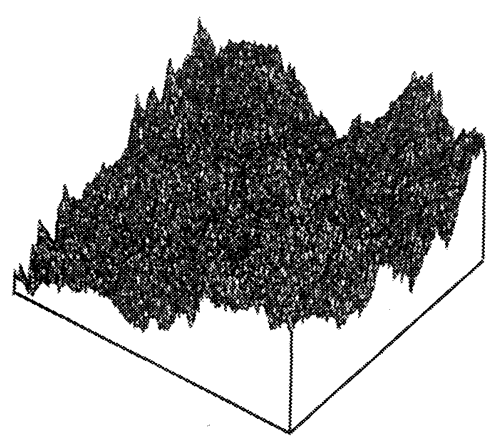

(c) $\sigma$ gauss $(\quad)=25000$

Fig. 9 Topographic maps of stone surface for Hurst exponent $H=0.54$ and various Gaussian random variable $\sigma$ gauss( )

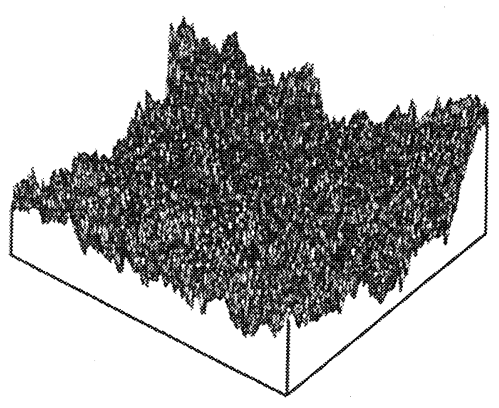

(a) $H=0.54$

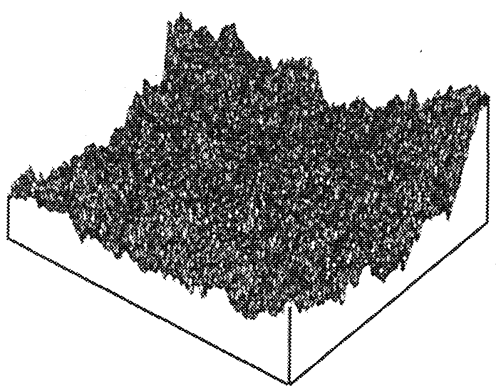

(b) $H=0.40$

Fig. 10 Topographic maps of stone surface for Gaussian random variable $\sigma$ gauss $(\quad)=20000$ and various Hurst exponent $H$
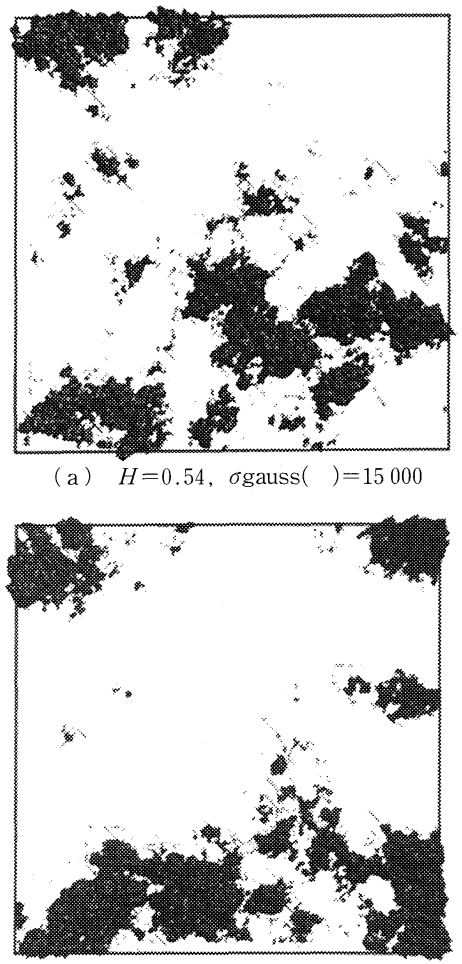

(b) $H=0.54, \sigma$ gauss ( ) $=20000$

Fig. 11 Distribution of abrasives on simulated stone surface 


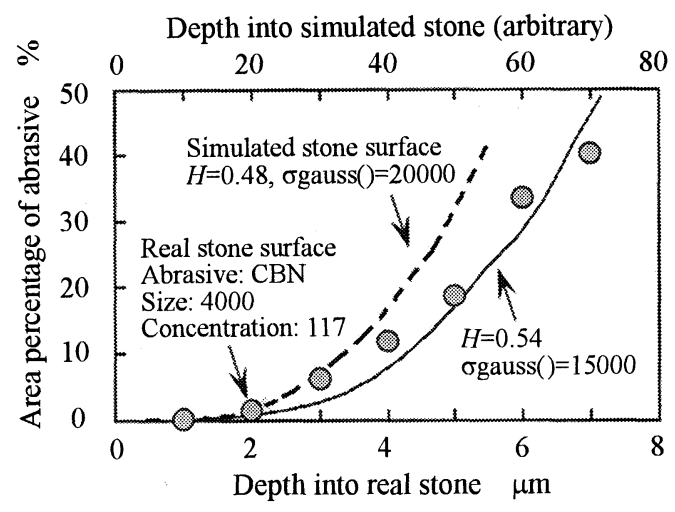

Fig. 12 Area percentage of abrasive occupying real and simulated stone surfaces

注目すると, ハースト指数が大きいほど起伏が激しく なっていることがわかる、これより, ハースト指数は 微小スケールの凹凸を生成するパラメータであること がわかる.したがって, 砥粒の高さ分布はハースト指 数により自在に表現されるものと思われる.

図 11 は図 9(a)，（b）に示した砥石作業面モデル を，ある高さの水平面で切った切断面に表れる島の集 合を示したものである. なお，図 9 のモデルは図 4 に 示したビトリファイド $\mathrm{CBN}$ 砥石作業面の砥粒分布の フラクタル次元の実測值 $D=1.46$ (ハースト指数 $H=$ 0.56)を用いて構成されたものである. 図中の大小さ まざまな島を作業面上の砥粒，島以外の部分を気孔部 分と見ると，実際の砥石作業面によく似ている。また， 外見上の類似に加えて, 砥粒分布の次元を一致させて モデルを構成したので，砥粒分布が自己相似的である ことも，実砥石作業面と同じである.

次に，砥石作業面の等高断面における実体部分が作 業面全体に占める割合を砥粒面積率とみなして，その 表面からの深さ分布を求めた. 図 12 は図 4 (b) に示 した実砥石作業面の砥粒面積率と図 11（a）のそれを 比較したものである。また，図 11 ( a ) と異なるハース 卜指数 $H=0.48$ とガウス確率変数 $\sigma$ gauss $(\quad)=20$ 000 の条件で構成した作業面モデルの砥粒面積率も図 12 に示す.ここで, モデルの表面からの深さは, $2^{8}$ 個 の解像度で分割された最小の正方格子の辺の長さを $0.1 \mu \mathrm{m}$ と換算して求めたものである. 図 12 より明ら かなように, 砥粒分布のフラクタル次元を一致させる と, 作業面の砥粒面積率もほぼ一致することがわか る.したがって, フラクタル幾何学のモデリング手法
を用いることにより，実際の砥石作業面に類似するト ポグラフィが構成できることが明らかになった。

\section{6. 結言}

ビトリファイド超砥粒砥石の作業面のトポグラフィ を構成する方法について検討した，開発した方法は， フラクタル形状を生成するアルゴリズムの一種, 中点 変位法と逐次ランダム加算法を用いるもので, 作業面 の砥粒分布のフラクタル次元をパラメータに, さまざ まなトポグラフィをコンピュータ上で生成することが できる、また，生成されたトポグラフィは実際の砥石 作業面と外見的に類似するだけでなく，砥粒面積率の 砥石表面からの深さ分布も一致する。したがって，本 方法はビトリファイド超砥粒砥石の形態設計におい て, 設計者のイメージを表現するモデリング・ツール として活用することができる.

\section{文献}

(1) Mizutani, K. et al., Simulation of Diamond Grinding Wheel to Characterize the Surface Topography, Journal of the Japan Society for Precision Engineering (in Japanese), Vol. 65, No. 4 (1999), pp. 581-585.

(2) Higuchi, M. et al., Fractal Characteristics of Grinding Wheel Surface, Journal of the Japan Society for Precision Engineering (in Japanese), Vol.62, No. 7 (1996), pp. 979-983.

(3) Higuchi, M. et al., Forming Factors of Fractal Grinding Wheel Topography, Journal of the Japan Society for Precision Engineering (in Japanese), Vol. 63, No. 7 (1997), pp. 1028-1032.

(4) Higuchi, M. et al., The Structural Design of Superfinishing Stone Using Fractal Modelling, Australasia-Pacific Forum on Intelligent Processing and Manufacturing of Materials, Vol.2 (1997), pp. 10721078.

( 5 ) Higuchi, M. et al., Development of Design Technology of Porous Superfinishing Stone Using Fractal Geometry (1st Report), Construction of Characteristic Equations Required for Design, Journal of the Japan Society for Precision Engineering (in Japanese), Vol. 65, No. 6 (1999), pp. 857-861.

(6) Higuchi, M. et al., Development of Design Technology of Porous Superfinishing Stone Using Fractal Geometry (2nd Report), Geometric Modeling of Stone Topography and Design Support System, Journal of the Japan Society for Precision Engineering (in Japanese), Vol. 67, No. 3 (2001), pp. 428-432.

( 7 ) Yamaguchi, T. et al., Fractal modeling method for $3 \mathrm{D}$ structure of vitrified-bonded wheel, Precision Engineering, Vol. 31 (2007), pp. 40-46.

(8) Peitgen, H. -O. and Saupe, D., The Science of Fractal Images, (1988), p. 71, Springer-Verlag, New York. 